CASTRO, E.M.; PINTO, J.E.B.P.; MELO, H.C.; SOARES, A.M.; ALVARENGA, A.A.; LIMA JÚNIOR, E.C. Aspectos anatômicos e fisiológicos de plantas de guaco submetidas a fotoperíodos. Horticultura Brasileira, Brasília, v.23, n.3, p.846-850, jul-set 2005.

\title{
Aspectos anatômicos e fisiológicos de plantas de guaco submetidas a diferentes fotoperíodos
}

\author{
Evaristo Mauro de Castro; José Eduardo B.P. Pinto; Hyrandir C. de Melo'; Ângela Maria Soares; \\ Amauri A. de Alvarenga; Érico de C. Lima Júnior \\ UFLA, C. Postal 37, 37200-000 Lavras-MG, E-mail: emcastro@ufla.br; 'Pós-graduando, Depto. Biologia, UFLA
}

\section{RESUMO}

O guaco (Mikania glomerata Sprengel) é espécie de uso medicinal conhecida pela atividade broncodilatadora. Muitos estudos têm evidenciado mudanças nas características anatômicas e fisiológicas de plantas medicinais sob influência de condições de radiação. Neste trabalho analisou-se a influência de fotoperíodos $(8 ; 12 ; 16$ e 20 h) na anatomia foliar, nos teores de clorofila e condutância estomática em três regiões da planta. Após 90 dias de tratamento, plantas adultas e com diferentes tamanhos influenciados pelos fotoperíodos foram submetidas às avaliações anatômicas e fisiológicas. Os teores de clorofila foram maiores nos fotoperíodos de 8 e $12 \mathrm{~h}$ nas regiões superior e mediana da planta e menores no fotoperíodo de $8 \mathrm{~h}$ na região basal. A condutância e densidade estomática apresentaram relação inversa ao aumento do fotoperíodo, sendo significativamente decrescente do ápice para a base da planta. Houve aumento da espessura da epiderme adaxial nas regiões mediana e basal da planta até o fotoperíodo de $16 \mathrm{~h}$. Nestas regiões houve aumento progressivo do parênquima esponjoso até o fotoperíodo de $20 \mathrm{~h}$. Verificouse modificações no tamanho e organização dos feixes vasculares influenciadas pelos fotoperíodos.

Palavras-chave: Mikania glomerata Sprengel, luz, clorofila, condutância estomática, anatomia foliar.
ABSTRACT

Anatomical and physiological aspects of guaco plants submitted to different photoperiods

Guaco (Mikania glomerata Sprengel) is a medicinal species known because of its bronchi-dilating activity. Many studies have indicated changes in anatomical and physiological characteristics of medicinal plants when submitted to different conditions of light. The effect of photoperiods $(8 ; 12 ; 16$ and $20 \mathrm{~h})$ on leaf anatomy, content of chlorophyll and stomatal conductance in distinct regions of guaco plants were analyzed. Adult plants of different sizes influenced by distinct photoperiods were submitted to anatomical and physiological analyses. 90 days after starting photoperiod treatments the chlorophyll content was higher in plants submitted to photoperiods of 8 and 12 hours in the superior and intermediary regions of plant, decreasing at $8 \mathrm{~h}$ of photoperiod treatment in the basal region of the plants. The conductance and stomatal density presented inverse relation to increase of photoperiod, decreasing from apical to basal regions of the plants. The thickness of the superior epidermis increased in the intermediary and basal regions of the plants submitted to a photoperiod up to $16 \mathrm{~h}$. These regions presented a progressive increase of the lacunose parenchyma thickness under a photoperiod up to $20 \mathrm{~h}$. The size and organization of the vascular bundles were influenced by the photoperiods.

Keywords: Mikania glomerata Sprengel light, chlorophyll, stomatal conductance, leaf anatomy.

(Recebido para publicação em 18 de agosto de 2004 e aceito em 8 de março de 2005)

$\mathrm{O}$ gênero Mikania é composto de aproximadamente 450 espécies, distribuídas em regiões tropicais da América, África e Ásia. Destas, cerca de 150 são encontradas no Brasil (Pereira, 1997). A espécie Mikania glomerata Sprengel (guaco) foi oficializada como fitofármaco na primeira edição da Pharmacopeia dos Estados Unidos do Brasil (Silva, 1929), e reconhecidamente, apresenta propriedades expectorantes e broncodilatadoras, sendo indicada no combate à tosse, asma, bronquite, rouquidão e outros sintomas associados a gripes e resfriados. A cumarina é uma das substâncias associadas a esse efeito (Ruppelt et al., 1991; Pereira, 1997).

Estudos com espécies de uso medicinal têm evidenciado plasticidades fi- siológicas e anatômicas em função das condições ambientais de cultivo (Clark e Menary, 1980; Letchano e Gosselin,1996). A luz é um dos fatores ambientais que mais influi no desenvolvimento vegetal, seja através de fotoestimulação da biossíntese de substâncias, fototropismo, fotomorfogênese ou fotoperiodismo (Larcher, 2000). O fotoperiodismo, ou a capacidade de um organismo detectar o comprimento do dia, torna possível a ocorrência de eventos em determinado momento do ano, permitindo, deste modo, resposta sazonal em detrimento de ciclos de luz e escuro (Taiz e Zeiger, 2004).

O efeito da duração diária da luz sobre o crescimento e desenvolvimento de plantas tem sido objeto de estudos exaustivos nas últimas décadas (Alvarenga e
Valio, 1989). Devido ao comprimento do dia variar consideravelmente dos trópicos para regiões de altas latitudes, o fotoperíodo vem mostrando efeito adaptativo significativo sobre o hábito, conformação vegetativa e distribuição das plantas no globo terrestre (Garner e Allard, 1920; Zimmermann e Brow, 1971). Efeitos de fotoperíodos sobre o tamanho, acúmulo de massa seca, área foliar e número de folhas foram observados por Wolf et al. (1990); Faria et al. (2000) e Castro e Alvarenga (2002).

A influência da luz sobre a anatomia foliar ocorre tanto nos primeiros estágios de desenvolvimento quanto no estagio adulto, devido a folha ser um "órgão plástico" e sua estrutura interna adaptar-se às condições de luz do ambiente (Whatley e Whatley, 1982). Lugg e 
Sinclair (1980) relataram que folhas de soja de nós superiores são mais espessas do que de nós inferiores. Além disto, o aumento da espessura das folhas pode ser promovido por modificações dos níveis de intensidade e duração luminosa durante o desenvolvimento (Friend e Pomeeroy, 1970; Lugg e Sinclair, 1980; Fails et al., 1982; Sert, 1992).

Em estudos realizados com plantas interagindo com diferentes intensidades ou durações de radiação é comum observar-se o efeito destes fatores interferindo substancialmente em algumas características fisiológicas das plantas, dentre as quais pode-se citar a condutância estomática, a fotossíntese e teor de clorofilas. Em estudos de fotoperíodo realizados com jacatupé (Pachyrrhizus tuberosus Lam. Spreng.), Alvarenga (1987) verificou que o fotoperíodo afeta os níveis de clorofila a, b e total dos folíolos laterais da quinta folha trifoliada sem, contudo, alterar a relação a:b.

O objetivo deste trabalho foi estudar o efeito de fotoperíodos, em três regiões da planta, sobre aspectos fisiológicos e anatômicos em guaco.

\section{MATERIAL E MÉTODOS}

Plantas de guaco com 60 dias de idade foram acondicionadas em câmaras de crescimento, em laboratório da UFLA, e submetidas aos tratamentos fotoperiódicos de 8; 12; 16 e 20 horas, realizados ao mesmo tempo em distintos compartimentos em parcelamento único. Foram utilizadas 16 repetições para cada fotoperíodo testado. Iluminação artificial foi fornecida por $75 \%$ de lâmpadas fluorescentes e $25 \%$ de lâmpadas do tipo Gro-Lux com intensidade média de radiação fotossinteticamente ativa de 225 ìmol. $\mathrm{s}^{-1} \cdot \mathrm{m}^{-2}$, determinada pelo uso de um quantômetro acoplado a um porômetro (STEADY STATE porometer LICOR $1600 \mathrm{M}$ ).

Em cada compartimento, foi adaptada uma cortina de tecido tipo "Black Out", dotado de um sistema temporizador, com acionamento e desligamento automático. A temperatura ambiente foi controlada por ar condicionado, registrando temperatura média de $25^{\circ} \mathrm{C}+3$ e umidade relativa do ar de
$15 \%$, monitorada através de psicrômetro. As plantas permaneceram 90 dias sob tratamento sendo regadas diariamente, para manter o substrato próximo à capacidade de campo.

Para determinação dos teores de clorofila foram tomadas, ao acaso, cinco plantas por tratamento. De cada planta foram selecionadas 9 folhas completamente expandidas, localizadas nas regiões superior, mediana e basal da planta, onde em cada planta e região do ramo, foram retirados três discos de 0,5 $\mathrm{cm}$ de diâmetro (ápice, meio e base da folha). Para quantificar as clorofilas a, b e total, utilizou-se a metodologia descrita por Arnon (1949), após a determinação da absorbância das amostras, com base nas leituras espectofotométricas a 663 e 645 çm, respectivamente para clorofilas a e b. Em seguida, procederamse a quantificação e os cálculos de mg de clorofila por grama de matéria fresca do tecido foliar, a partir das equações: Clorofila $\mathrm{a}=(12,7 \times \mathrm{A} 663-2,69 \mathrm{x}$ A645) x V/1000W; Clorofila b $=(22,9$ x A645 - 4,68 x A663) x V/1000W; Clorofila total $=(20,2 \times \mathrm{A} 645+8,02 \times$ A663) $x$ V/1000W. Sendo, $A=$ absorbância dos extratos no comprimento de onda determinado; $\mathrm{V}=$ volume final do extrato clorofila-acetona e $\mathrm{W}=$ matéria fresca em gramas do material vegetal utilizado.

A condutância estomática foi determinada em oito plantas, nas três posições do ramo, na epiderme abaxial das folhas utilizadas para o estudo anatômico, com auxílio de um porômetro (STEADY STATE porometer LICOR 1600M).

Os estudos anatômicos foram efetuados em três posições do ramo: na folhas mais jovens (recém expandidas), nas folhas intermediárias, do terço mediano superior das plantas e folhas mais velhas retiradas da base da planta. De oito plantas foram retiradas uma folha, onde foram extraídas seções de $0,5 \mathrm{~cm}^{2}$, em sua região mediana, e efetuados estudos anatômicos, com base no exame microscópico de cortes transversais e paradérmicos obtidos à mão livre. As seções foram clarificadas em solução a $50 \%$ de hipoclorito de sódio, e em seguida, lavadas em água destilada, neutralizadas em água acética 1:500 e mon- tadas em glicerina a 50\%. O corante usado foi a mistura azul de astrasafranina, conforme metodologia descrita por Bukastsh (1972). A partir das secções transversais, com o auxílio de ocular micrométrica, foram feitas vinte medições das espessuras das epidermes abaxial, adaxial, parênquimas lacunoso e paliçádico em cinco plantas e posições da planta.

Para o sistema vascular da folha, foram realizadas medições da altura e largura do maior e mais centralizado feixe vascular da nervura principal, efetuando-se a contagem do número de vasos do xilema de cinco plantas e duas seções por planta de cada região da planta (apical, intermediária e basal). Cortes paradérmicos foram desenvolvidos para análise da epiderme da face abaxial, utilizando-se o corante safranina hidroalcoólica, onde a contagem do número de estômatos foi realizada utilizando-se câmara clara e microscópio OLIMPUS CBB (Labouriau et al., 1961). Seis campos da região mediana de cada folha, nas três posições da planta foram analisadas em oito folhas escolhidas ao acaso das três regiões da planta. Para o estudo do feixe vascular foram escolhidos os maiores e mais centralizados na nervura central das folhas.

$\mathrm{O}$ experimento foi conduzido em delineamento experimental inteiramente casualizado. Após análise de variância dos dados, utilizou-se o teste de Tukey a 5\% para separação das médias em classes distintas.

\section{RESULTADOS E DISCUSSÃO}

Analisando o comportamento do teor de clorofilas a, b, e total, nos diferentes fotoperíodos (Tabela 1), observou-se que foram maiores nos fotoperíodos de 8 e 12 horas na região superior, não sendo observado o mesmo na região mediana do ramo, onde apenas os teores de clorofilas totais foram maiores nos fotoperíodos de 8 e 12 horas. No entanto, na região basal, os maiores teores de clorofila foram encontrados nas folhas expostas aos fotoperíodos de 12; 16 e $20 \mathrm{~h}$. Esta maior concentração de clorofilas ocorrida na região basal da planta, provavelmente, decorreu do auto-sombreamento foliar 
Tabela 1. Teores de clorofila a, b e total (mg/g de matéria fresca) e relação clorofila a/b em mudas de guaco submetidas a diferentes fotoperíodos, nas três posições do ramo após 90 dias de tratamento. Lavras, UFLA, 2004.

\begin{tabular}{ccccc}
\hline Região superior & Clorofila $\mathbf{a}$ & Clorofila b & razão a/b & Clorofila total \\
\hline 8 horas & $1,282 \mathrm{a}$ & $0,678 \mathrm{a}$ & $1,904 \mathrm{~b}$ & $1,960 \mathrm{a}$ \\
12 horas & $1,321 \mathrm{a}$ & $0,578 \mathrm{a}$ & $2,288 \mathrm{a}$ & $1,899 \mathrm{a}$ \\
16 horas & $0,782 \mathrm{~b}$ & $0,378 \mathrm{~b}$ & $2,104 \mathrm{a}$ & $1,160 \mathrm{~b}$ \\
20 horas & $0,614 \mathrm{~b}$ & $0,357 \mathrm{~b}$ & $1,818 \mathrm{~b}$ & $0,970 \mathrm{~b}$ \\
\hline Região mediana & Clorofila $\mathbf{a}$ & Clorofila $\mathbf{b}$ & razão $\mathbf{a} / \mathbf{b}$ & Clorofila total \\
\hline 8 horas & $1,696 \mathrm{~b}$ & $0,897 \mathrm{a}$ & $1,905 \mathrm{~b}$ & $2,593 \mathrm{a}$ \\
12 horas & $1,919 \mathrm{a}$ & $0,810 \mathrm{a}$ & $2,369 \mathrm{a}$ & $2,728 \mathrm{a}$ \\
16 horas & $1,577 \mathrm{~b}$ & $0,685 \mathrm{a}$ & $2,322 \mathrm{a}$ & $2,262 \mathrm{~b}$ \\
20 horas & $1,523 \mathrm{~b}$ & $0,705 \mathrm{a}$ & $2,177 \mathrm{a}$ & $2,228 \mathrm{~b}$ \\
\hline Região basal & Clorofila a & Clorofila b & razão a/b & Clorofila total \\
\hline 8 horas & $1,324 \mathrm{~b}$ & $0,695 \mathrm{~b}$ & $1,904 \mathrm{a}$ & $2,018 \mathrm{~b}$ \\
12 horas & $1,873 \mathrm{a}$ & $0,954 \mathrm{a}$ & $2,018 \mathrm{a}$ & $2,826 \mathrm{a}$ \\
16 horas & $1,876 \mathrm{a}$ & $1,141 \mathrm{a}$ & $1,640 \mathrm{a}$ & $3,020 \mathrm{a}$ \\
20 horas & $2,054 \mathrm{a}$ & $1,152 \mathrm{a}$ & $1,782 \mathrm{a}$ & $3,205 \mathrm{a}$ \\
\hline
\end{tabular}

Médias seguidas de mesma letra, na coluna, não diferem entre si pelo teste de Tukey a $5 \%$.

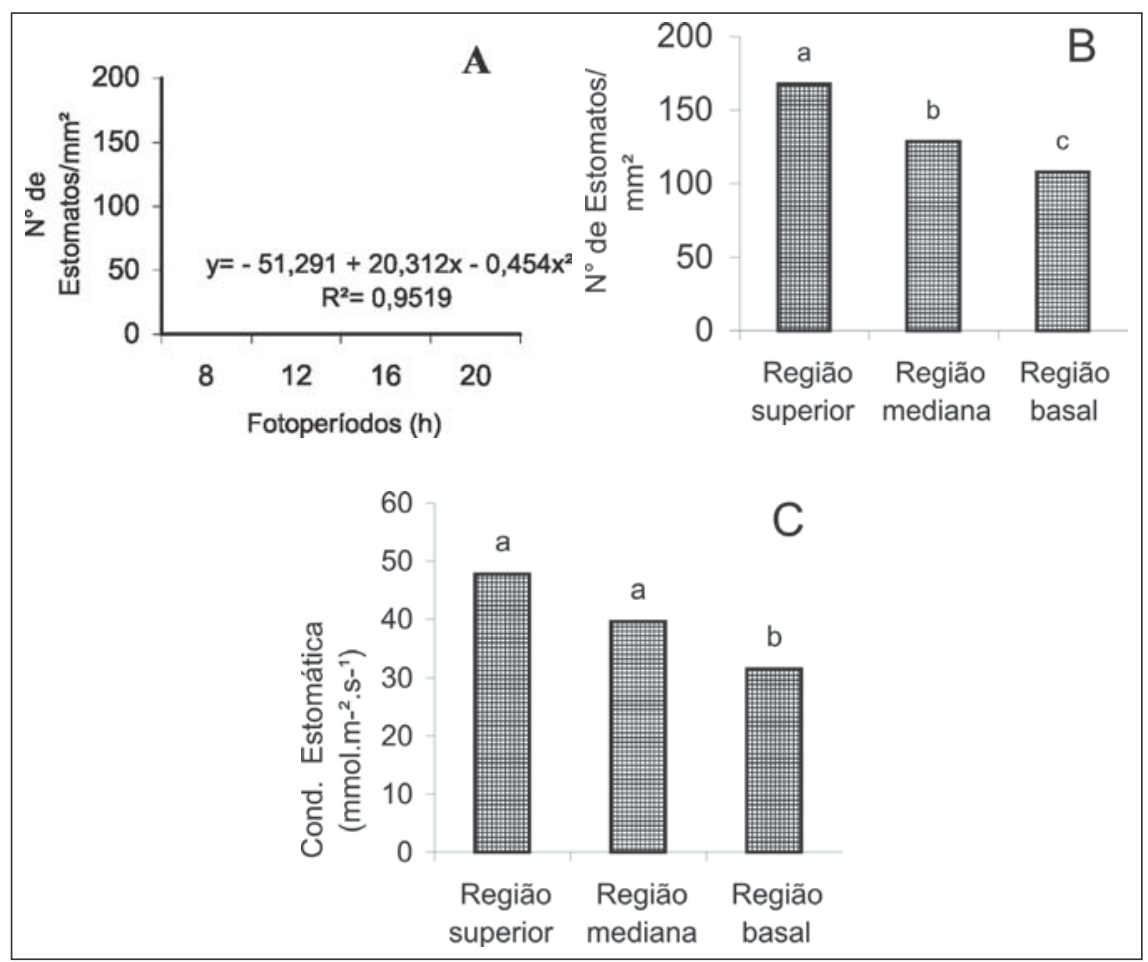

Figura 1. Média do número de estomatos $/ \mathrm{mm}^{2}$ entre os diferentes fotoperiodos (A) e entre as diferentes regiões da plantas (B) e condutância estomática entre as diferentes regiões da planta (C). Médias seguidas de mesma letra não diferem entre si pelo teste de Tukey a $5 \%$. Lavras, UFLA, 2004.

desta região, em função da arquitetura cônica da planta de guaco e aos nós mais curtos na região basal. Possivelmente, os maiores teores de clorofila nos fotoperíodos mais longos compensem a da falta de luz causada pelo autosombreamento ao longo do dia. Segundo Whatley e Whatley (1982), sob auto- lhantes foram encontrados por Herath e Ormrod (1979); Faria et al. (2000) e Castro e Alvarenga (2002). Pode-se sugerir que sob fotoperíodos mais curtos, as folhas das regiões superior e mediana de plantas de guaco conseguem manter os seus teores de clorofila, provavelmente por estarem expostas a menor período de luz, reduzindo com isto a ocorrência de processos foto-oxidativos.

Nas figuras 4A, 4B, 4C e 4D, observa-se que para os fotoperíodos de $8 \mathrm{e}$ 12 horas as células epidérmicas apresentaram paredes anticlinais acentuadamente sinuosas e aparentemente com maior dimensão em relação aos fotoperíodos de 16 e 20 horas.

Houve um crescente aumento da densidade estomática com o aumento do fotoperíodo (Figura 1A), e também da região basal em direção à região superior da planta (Figura 1B). Provavelmente a sombra causada pelas folhas das regiões superiores causou modificações estruturais nas folhas basais para adaptação às condições de sombra. Estes resultados estão de acordo com diversos autores que observaram que o número de estômatos pode variar entre folhas da mesma espécie crescendo em diferentes condições ambientais (Wilkinson e Beard, 1975; Cohen et al., 1982; Sert, 1992). Segundo Larcher (2000), é comum a tendência do aumento da densidade estomática em folhas exposta a maior radiação solar. Observa-se (Figura 1C) que a condutância estomática tem tendência similar à densidade estomática nas diferentes regiões do ramo (Figura 1B), corroborando com os resultados obtidos por Hoflacher e Bauer (1982) para folhas expostas ao sol, em relação àquelas sombreadas. $\mathrm{O}$ aumento da densidade estomática em plantas de guaco expostas a fotoperíodos mais longos, visto neste trabalho, se assemelha ao comportamento de muitas espécies, quando submetidas a alta intensidade de radiação solar (Larcher, 2000).

Houve aumento progressivo da espessura da epiderme adaxial, nas regiões mediana e basal da planta, concomitante ao aumento do fotoperíodo até 16 horas, havendo queda no fotoperíodo de 20 h (Figura 2). Esse comportamento não foi observado na região superior da planta, observando-se aumento linear até 20 horas (Figura 2). Não foi observado grande efeito do fotoperíodo no espessamento da epiderme abaxial, di- 
ferentemente da adaxial, principalmente quando se considerou as regiões basal e mediana da planta (Figura 2). Apesar da epiderme abaxial ter tido um menor grau de resposta, se comparada à epiderme adaxial, à duração fotoperiódica (Figura 2), foram observadas variações para sinuosidade e superfície específica nas células dessa epiderme (Figuras 4A, 4B, 4C, 4D). Outras alterações de células epidérmicas, quanto a disponibilidade de luz, foram constatadas por Vogelmann et al. (1996).

Os parênquimas paliçádico e esponjoso são tecidos que apresentam grande capacidade de respostas aos estímulos de luz, influenciando portanto, a espessura foliar. Segundo Taiz e Zeiger (2004), as propriedades das células paliçádicas permitem a passagem direta da luz, e as propriedades das células do parênquima esponjoso, que servem à dispersão da luz, determinando uma absorção mais uniforme através da folha.

Na Figura 3 observa-se aumento linear do parênquima esponjoso em relação ao fotoperíodo, exceto para as folhas da região superior da planta, nas quais, houve decréscimo da espessura a partir do fotoperíodo de 16 horas. O mesmo comportamento, apesar de menor intensidade, pode ser observado para o parênquima paliçádico, pois na região superior e mediana do ramo houve tendência de decréscimo da espessura foliar a partir do fotoperíodo de 16 horas (Figuras 3, 4I, 4J, 4K e 4L). O aumento da espessura foliar com o aumento do fotoperíodo é semelhante ao comportamento das folhas quando expostas a condições de sol e sombra, onde aquelas expostas ao sol tendem a aumentar a espessura foliar, como observado por Hoflacher e Bauer (1982). Essas modificações podem ocorrer pela variação das divisões celulares, padrão de expansão celular e, consequentemente, modificações na espessura foliar (Fails et al., 1982; Verbelen e Greef, 1979).

Em plantas submetidas aos diferentes fotoperíodos observou-se modificações no tamanho e arranjo dos feixes vasculares (Figuras 4E, 4F, 4G, 4H). No fotoperíodo de oito horas observou-se a ocorrência do feixe vascular de menor tamanho e com menor número de ele-
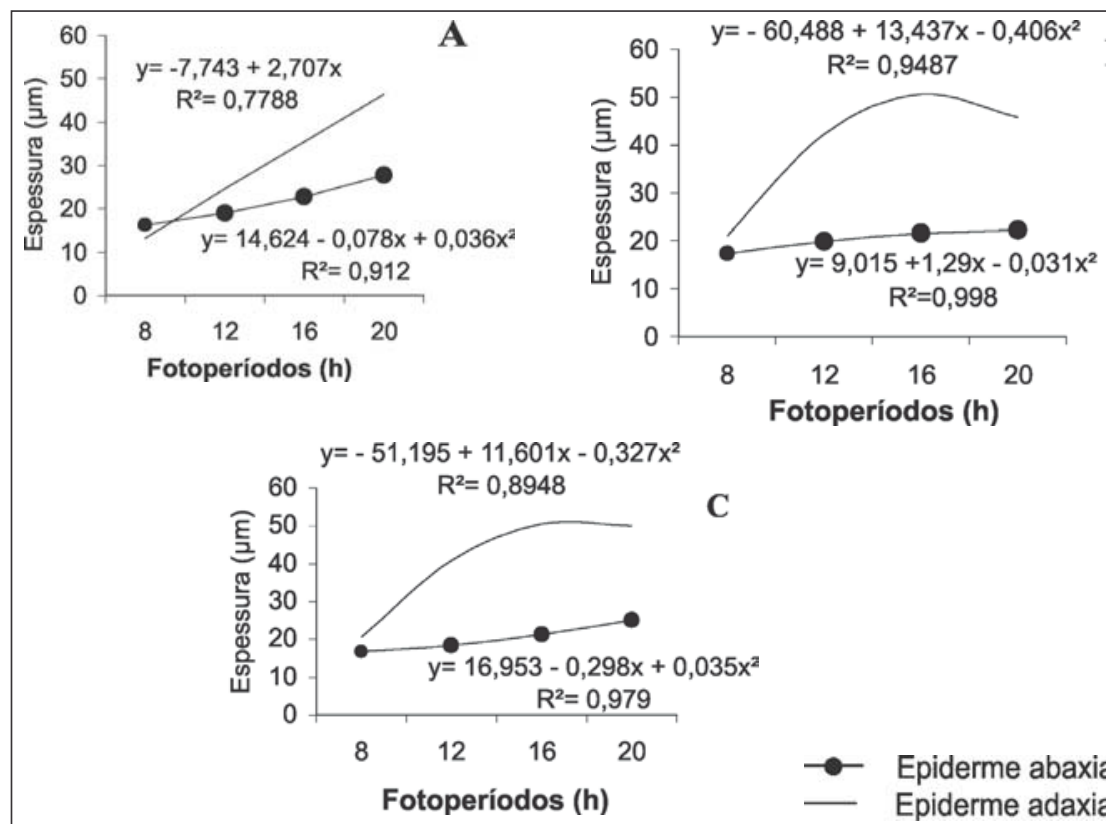

Epiderme abaxial Epiderme adaxial

Figura 2. Relação entre os fotoperíodos $(8,12,16$ e $20 \mathrm{~h})$ e espessura de tecidos epidérmicos em diferentes posições do ramo (A: superior, B: mediana, C: basal) de guaco. Lavras, UFLA, 2004.

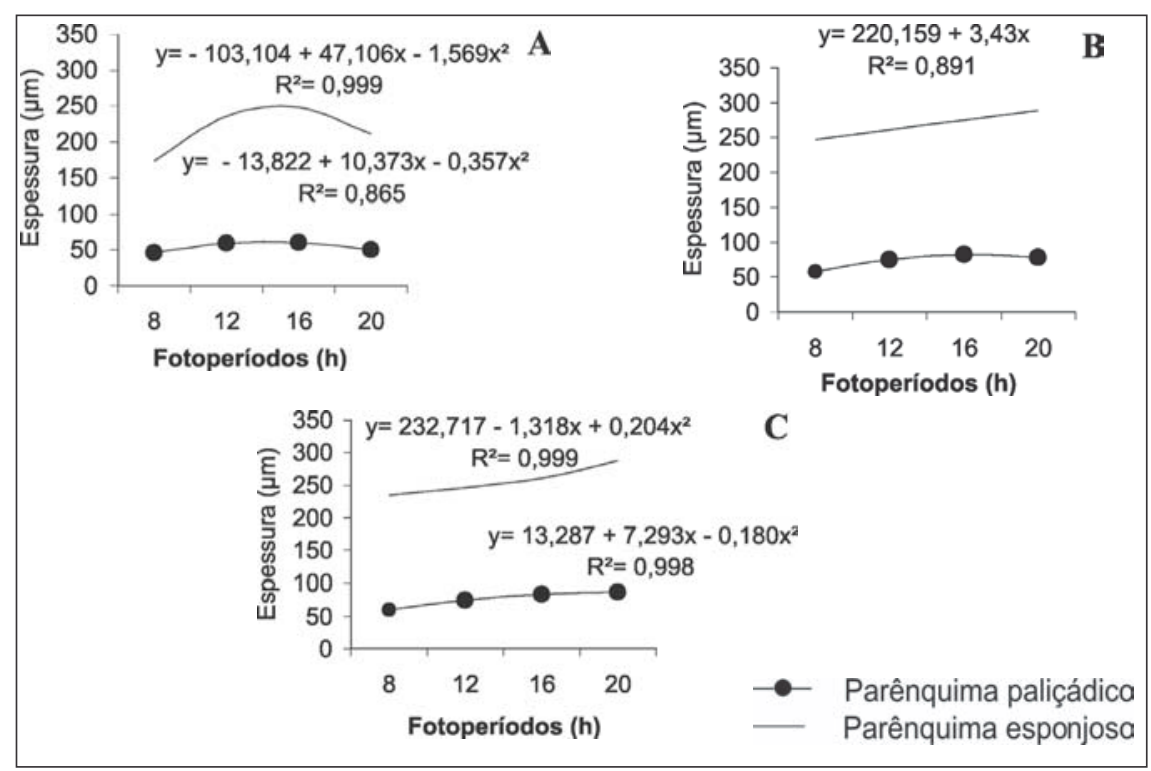

Figura 3. Relação entre os fotoperíodos (8,12,16 e 20 horas) e a espessura dos tecidos foliares de guaco em três regiões da planta (A: superior, B: mediana, C: basal). Lavras, UFLA, 2004.

mentos de vaso (Figura 4E), em 12 h e $20 \mathrm{~h}$ (Figuras 4F e 4H), feixes de tamanho intermediário, em relação aos demais tratamentos, e com elementos de vaso muito próximos, e em 16 h, o feixe com maior tamanho em altura e com elementos de vaso mais dispersos (Figura 4G). Esses resultados sugerem que o fotoperíodo de 16 horas possivelmente seja o mais adequado para um ótimo desenvolvimento dos feixes vasculares em plantas de guaco. De acordo com
Baas (1982); Baas e Schweingruber (1987); Carlquist (1988); Alves e Angyalossy-Alfonso (2000), os fatores ambientais afetam as dimensões e até mesmo o arranjo dos elementos vasculares. Quando a planta está sujeita a algum tipo de estresse, a diminuição dos vasos pode garantir aumento na segurança do transporte.

$\mathrm{O}$ aumento da densidade estomática (Figura 1A), associado ao aumento da espessura de tecidos foliares (Figuras 2 


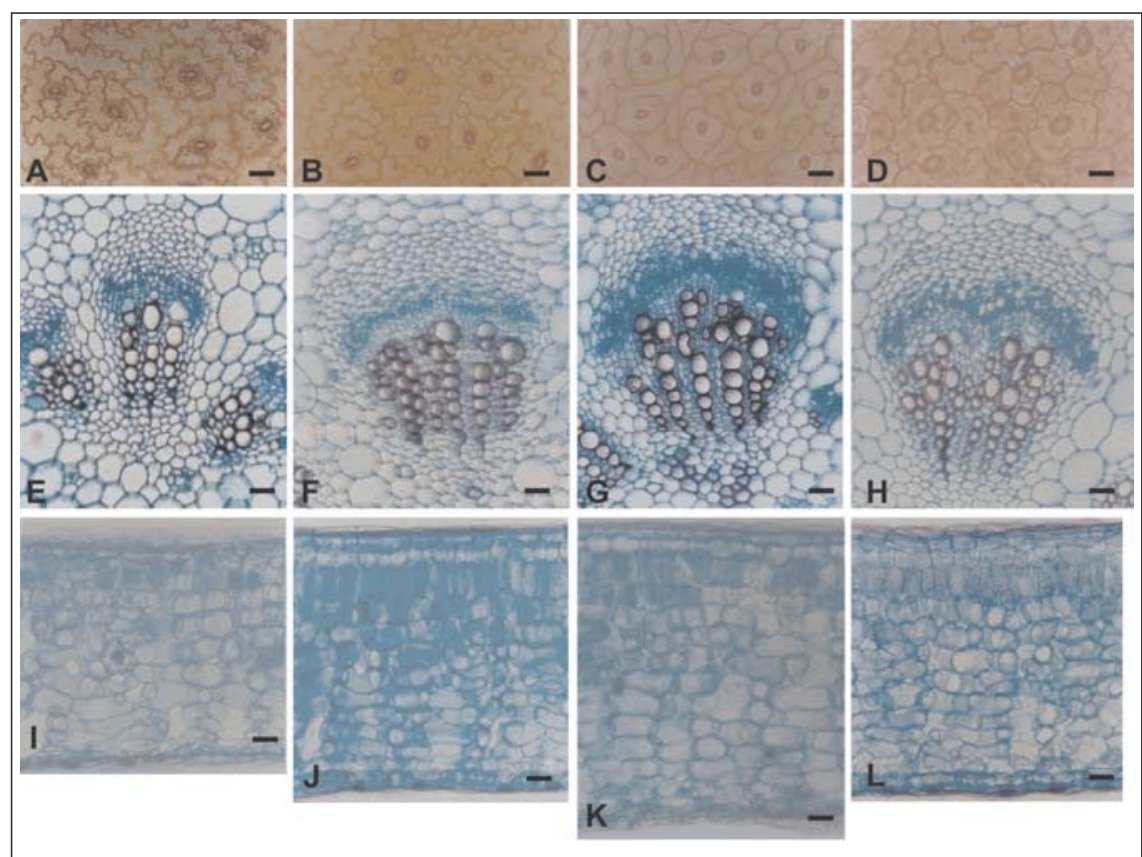

Figura 4. Seções paradérmicas da epiderme da face abaxial das folhas (A, B, C, D), seções transversais do feixe vascular na região da nervura central (E, F, G, H) e seções transversais da lâmina foliar (I, J, K, L) de guaco submetidas a diferentes condições de fotoperíodos: A, E, I: fotoperíodo de 8 h; B, F, J: fotoperíodo de 12 h; C, G, K: fotoperíodo de 16 h; D, H, L: fotoperíodo de 20 h. Barras=50ìm. Lavras, UFLA, 2004.

e 3), à medida em que havia aumento do fotoperíodo, são evidências de similaridade comportamental das plantas de guaco a diversas outras espécies quando submetidas a altas intensidades de radiação solar.

O aumento da espessura em vários tecidos, até o fotoperíodo de 16 h, e a diminuição dessa espessura no fotoperíodo de $20 \mathrm{~h}$, como visto para epiderme adaxial nas regiões mediana e basal da planta (Figura 2), para parênquimas esponjoso, na região superior da planta, e paliçádico, nas regiões superior e mediana da planta (Figura 3) e para tamanho dos feixes vasculares (Figura 4E, 4F, 4G, 4H), são indicativos que o fotoperíodo de $16 \mathrm{~h}$ seja o que propicia o maior desenvolvimento vegetativo de plantas de guaco.

\section{LITERATURA CITADA}

ALVARENGA, A.A. Estudo de alguns aspectos do desenvolvimento do feijão jacatupé (Pachyrrhizus tuberosus Lam. Spreng). 1987. 74 f. (Tese doutorado) - Universidade Estadual de Campinas, Campinas.

ALVARENGA, A.A.; VALIO, F.M. Influence of temperature and photoperiod on flowering and tuberous root formation of Pachyrrhizus tuberosus. Annals of Botany, v.64, n.1, p.411-414, 1989
ALVES, E.S.; ANGYALOSSY-ALFONSO, V. Ecological trends in the wood of some Brazilian species 1: growth rings and vessels. IAWA Journal, v.21, p.3-30, 2000.

ARNON, D.I. Cooper enzymes in isolated choloroplasts. Polyphenoloxidase in Beta vulgaris. Plant Physiology, v.24, n.1, p.1-15, 1949.

BAAS, P. Systematic, phylogenetic and ecological wood anatomy - History and perspectives. In: New perspectives in wood anatomy. (P. Baas, ed.). The Hangue Martinus Nijhoff Publishers, Leiden, p.2358. 1982.

BAAS, P.; SCHWEINGRUBER, F.H. Ecological trends in the wood anatomy of trees, shrubs and climbers from Europe. IAWA Bulletin n.s., v.8, p.245-274, 1987.

BUKASTSH, F. Bemerkungren zur doppelfärbung astrablausafrina. Microkosmos, Stuttgart. v.61, p.255, 1972.

CARLQUIST, S. Comparative wood anatomy: systematic, ecological and evolutionary aspects of dicotyledons wood. Springer Verlag, Berlin. 1988. CASTRO, A.H.F.; ALVARENGA, A.A. Influência do fotoperíodo no crescimento inicial de plantas de confrei (Symphytum officinale L.). Ciência e agrotecnologia, v.26, n.1, p.77-86, 2002.

CLARK, R.J.; MENARY, R.C. Environmental effects on Peppermint (Mentha piperia L.) I. Effects of daylength, photon flux density, might temperature and day temperature on the yield and composition of peppermint oil. Australian Journal of Plant Physiology, v.7, n.6, p.685-692, 1980.

COHEN, C.I.; CHILCOTE, D.O.; FRAKES, R.V.

Leaf anatomy and stomatal characteristic of four tall fescue selections differing in forage yield. Crop Science, v.22, n.4, p.704-708, 1982. Anatomy and morphology of sun and Shade-grow Ficus benjamina. Journal of the American Society Horticultural Science, v.107, n.5, p.754-757, 1982.
FAILS, B.S.; LEWIS, A.J.; BARDEN, J.A.
FARIA, L.L.; ALVARENGA, A.A.; CASTRO, E.M.; SOBRINHO, J.C.S. Alguns aspectos morfofisiológicos do feijão jacatupé (Pachyrrhizus tuberosus Lam. Spreng). Ciência e Agrotecnologia, v.24, n.3, p.688-695, 2000. FRIEND, D.J.C.; POMEEROY, M.E. Changes in cell size and number associated with the effects of light intensity and temperature on the leaf morphology of wheat. Canadian Journal of Botany, v.48, n.1, p.85-91, 1970.

GARNER, W.W.; ALLARD, H.A. Effect of relative length of day and night and others factors of the environment on grown and reproduction in plants. Journal of Agricultural Research, v.18, n.11, p.553-606, 1920.

HERATH, H.M.W.; ORMROD, D.P. Effects of temperature and photoperiod on Whinged beans (Psophocarpus tetragonolobus L.). Annals of Botany, New York, v.43, n. 6, p.107-114, 1979. HOFLACHER, H.; BAUER, H. light acclimation in leaves of the juvenile and adult life phases of ivy (Hedera helix). Physiologia Plantarum, v. 56, p.177-182, 1982.

LABOURIAU, L.G.; OLIVEIRA, J.G.; SALGADO-LABOURIAU, M.L. Transpiração de Schizolobium parahyba (Vell) Toledo I. Comportamento na estação chuvosa, nas condições de Caeté, Minas Gerais. Anais da Academia Brasileira de Ciência, v.33, n.2, p.237-257, 1961.

LARCHER, W. Ecofisiologia Vegetal. São Carlos, Rima, 2000. 531p.

LETCHAND, W.; GOSSELIN, A. transpiration essential oil gland, epicuticular wak and morphology of Thymus vulgaris are influenced by light intensity and water supply. Journal Horticultural science, v.71, n-1, p.123-134, 1996. LUGG, D.G.; SINCLAIR, T.R. Seasonal changes in morphology and anatomy of field-grow soybean leaves. Crop Science, v.20, n.2, p.191-195, 1980. PEREIRA, A.M.S. Propagação e co-cultivo de células como fatores predisponentes à produção de cumarina em Mikania glomerata Sprengel (guaco). 1997. 82 f. (Tese doutorado) - UNESP, Botucatu. RUPPELT, B.M.; PEREIRA, E.F.; GONÇALVES, L.C.; PEREIRA, N.A. Pharmacological screening of plants recommended by folk medicine as antisnake venom I. Analgesic and anti-inflammatory activities. Memórias do Instituto Oswaldo Cruz 86 (Suppl. II): p.203-205, 1991.

SERT, M.A. Anatomia foliar e teores de clorofila em três variedades de soja (Glycine Max L.) e dois níveis de radiação solar. 1992. 66 f. (Tese mestrado) - UFV, Viçosa.

SILVA, R.A.D. Pharmacopeia dos Estados Unidos do Brasil. São Paulo: Companhia Editora Nacional, 1929, p.237.

TAIZ, L.; ZEIGER, E. Fisiologia Vegetal. Porto Alegre: Artmed, 2004. 719 p.

VERBELEN, J.P.; GREEF, I.A. Leaf development of Phaseolus vulgaris L. in light and in darkness. American Journal of Botany, v.66, n.8, p.970-976, 1979.

VOGELMANN, T.C.; BJORN, L.O. Plant as light traps. Phisiologia Plantarum, v.68, p.704-708, 1996. WILKINSON, J.F.; BEARD, J.B. Anatomical responses of "Merion" Kentucky bluegrass and "Penn lawn" red fescue at reduced ling intensities. Crop Science, v.15, n.1, p.189-194, 1975.

WHATLEY, F.H.; WHATLEY, F.R. A Luz e a vida das plantas. São Paulo: EPU-EDUSP, 1982. 101 p. (Temas de Biologia, 30)

WOLF, S.; MARANI, A; RUDICH, J. Effects of temperature and photoperiod on assimilate partitioning in potato plants. Annals of Botany, v.66, p.513-520, 1990. 